\title{
Electronic Structure Modulation in Cationic Boron Formazanate Complexes
}

\author{
[a] Dr. R. R. Maar, B. D. Katzman, Dr. P. D. Boyle, Prof. Dr. V. N. Staroverov, and Prof. Dr. J. B. Gilroy \\ Department of Chemistry and The Centre for Advanced Materials and Biomaterials Research (CAMBR) \\ The University of Western Ontario \\ 1151 Richmond Street North, London, Ontario N6A 5B7 (Canada) \\ E-mail: joe.gilroy@uwo.ca \\ $\dagger \quad$ These authors contributed equally to this work.
}

Ryan R. Maar ${ }^{\dagger}$, Benjamin D. Katzman ${ }^{\dagger}$, Paul D. Boyle, Viktor N. Staroverov, and Joe B. Gilroy*[a]

Supporting information for this article is given via a link at the end of the document.

\begin{abstract}
Incorporation of cationic boron atoms into molecular frameworks is an established strategy for creating chemical species with unusual bonding and reactivity but is rarely thought of as a way of enhancing molecular optoelectronic properties. We have synthesized a series of boron formazanate complexes with the aim to demonstrate that the wavelengths, intensities, and type of the first electronic transitions in BN heterocycles can be modulated by varying the cationic charge, coordination number, and supporting ligands at the boron atom. UV-vis absorption spectroscopy measurements and density-functional calculations show that these modulations are caused by changes in the geometry and extent of $\pi$ conjugation of the boron formazanate ring. These findings offer general guiding principles for the design of optoelectronic materials based on $\pi$-conjugated heterocycles containing boron and other main-group elements.
\end{abstract}

The ability of main-group elements to form stable compounds with unusual structure, bonding, and reactivity has powered a resurgence of synthetic main-group chemistry ${ }^{[1]}$ and challenged the supremacy of transition metals in catalysis, ${ }^{[2]}$ bond- ${ }^{[3]}$ and small-molecule activation techniques, ${ }^{[4]}$ and the development of functional materials. ${ }^{[5]}$ In the field of functional materials in particular, incorporation of main-group elements into $\pi$-conjugated frameworks is becoming a powerful strategy for the development of new optoelectronic materials. ${ }^{[6]}$

Owing to its electron-deficient nature, boron is often combined with organic fragments to modulate the energies of the frontier orbitals. The resulting compounds have been suggested as promising candidates for use in organic electronics. ${ }^{[7]}$ To modulate the optoelectronic properties of these molecules, suitable methods to enhance Lewis acidity at the boron centre are required. The traditional approaches rely on installing anti-aromatic scaffolds around boron atoms ${ }^{[8],[9]}$ or using electron-withdrawing substituents. ${ }^{[10]}$ Another strategy consists in varying the charge and coordination number of boron atoms ${ }^{[11]}$ and produces two- ${ }^{[12],[13]}$ three-, ${ }^{[14],[15]}$ and fourcoordinate ${ }^{[16],[17]}$ cations and dications such as $1^{+}-6^{2+} \cdot{ }^{[11 a, 18]}$ The method of charge variation is familiar within the catalysis arena $^{[19]}$ and fundamental research on the structure and bonding of cationic boron compounds ${ }^{[20]}$ but remains relatively unexplored in the field of optoelectronic materials.

One extremely useful platform for developing the chemistry of main-group elements is furnished by formazanate ligands. ${ }^{[21],[22]}$ Boron difluoride formazanate complexes display easily tunable optoelectronic properties ${ }^{[23]}$ and find numerous applications as cell-imaging agents, ${ }^{[24]}$ electrochemiluminescent
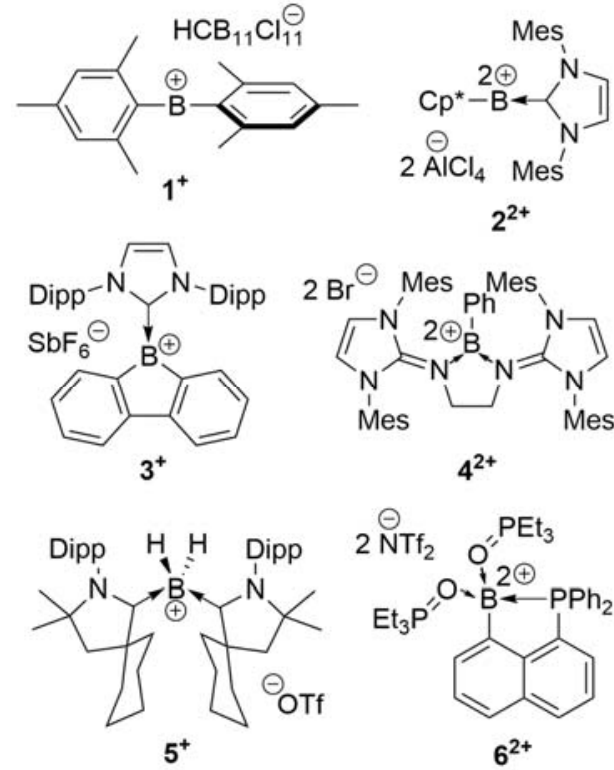

emitters, ${ }^{[23 e, 25]}$ and precursors to a wide variety of BN heterocycles with unprecedented structure and functionality. ${ }^{[26]}$

Here, we demonstrate that the variation of cationic charge and coordination number of boron atoms is a very effective approach for tuning the electronic structure and optical properties of boron formazanate complexes such as 7-14. This demonstration is the first of its kind for BN heterocycles and can be extended to other main-group elements and similar ligand families (e.g., dipyrrin, aza-dipyrrin, and $\beta$-diketiminates).

Boron formazanate adducts $7-10^{+}, 12^{+}$, and $13^{2+}$ were synthesized according to Scheme 1 and characterized using multinuclear NMR, FT-IR, and UV-Vis absorption spectroscopies, as well as high-resolution mass spectrometry (Figures S1-S24). BPhF formazanate 7 was prepared by heating 1,5-( $p$-tolyl)-3phenylformazan at $60^{\circ} \mathrm{C}$ with excess $\mathrm{N}(\mathrm{iPr})_{2} \mathrm{Et}$ and a mixture of TMSCl and $\mathrm{KBPhF}_{3}$ in $\mathrm{CH}_{2} \mathrm{Cl}_{2} / \mathrm{CH}_{3} \mathrm{CN}$ for $36 \mathrm{~h}$. The crude product was purified via column chromatography to produce complex 7 in $75 \%$ yield. This transformation was accompanied by a colour change from red to purple, a loss of the $\mathrm{NH}$ resonance in the ${ }^{1} \mathrm{H}$ NMR spectrum of 1,5-(p-tolyl)-3phenylformazan $(\delta=15.51)$, and the appearance of broad singlets at $2.9 \mathrm{ppm}$ in the ${ }^{11} \mathrm{~B}\left\{{ }^{1} \mathrm{H}\right\}$ NMR spectrum and $-164.6 \mathrm{ppm}$ in the ${ }^{19} \mathrm{~F}$ NMR spectrum of 7 . Halide exchange between complex 7 and $\mathrm{BCl}_{3}$ afforded $\mathrm{BPhCl}$ formazanate 8 as a dark-purple solid in quantitative yield. This was confirmed by 

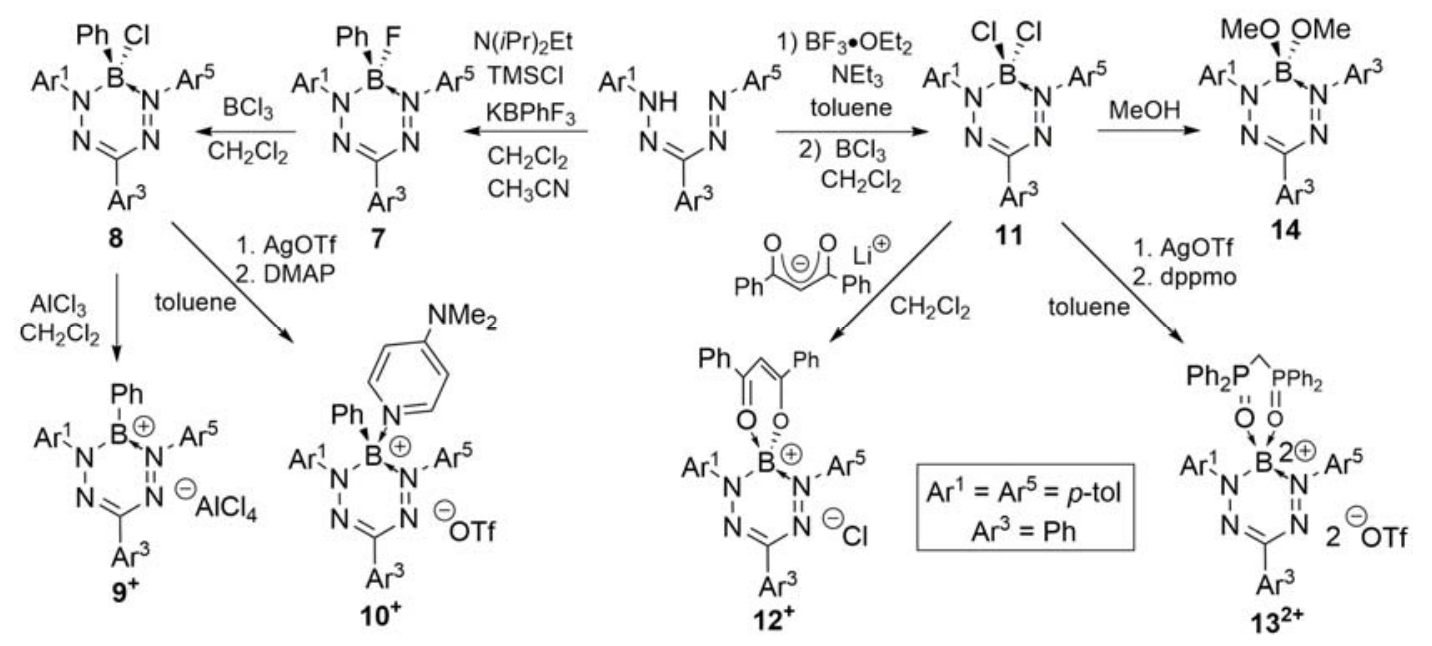

Scheme 1. Syntheses of boron formazanates 7-14. DMAP = 4-dimethylaminopyridine, OTf = trifluoromethanesulfonate, dppmo = bis(diphenylphosphino)methane dioxide.

the presence of a singlet at $2.4 \mathrm{ppm}$ in the ${ }^{11} \mathrm{~B}\left\{{ }^{1} \mathrm{H}\right\} \mathrm{NMR}$ spectrum and absence of signals in the ${ }^{19} \mathrm{~F}$ NMR spectrum for complex 8 . $\mathrm{BPhCl}$ formazanate 8 was converted to the threecoordinate (borenium) cation $\mathbf{9}^{+}$by treatment with an equimolar amount of $\mathrm{AlCl}_{3}$ in $\mathrm{CH}_{2} \mathrm{Cl}_{2}$. Complex $\mathbf{9}^{+}$was isolated as an airand moisture-sensitive dark-purple solid in $98 \%$ yield. The presence of a three-coordinate boron centre was confirmed by a broad signal centred at $35.5 \mathrm{ppm}$ in the ${ }^{11} \mathrm{~B}\left\{{ }^{1} \mathrm{H}\right\}$ NMR spectrum and a sharp singlet at $103.6 \mathrm{ppm}$ in the ${ }^{27} \mathrm{Al}\left\{{ }^{1} \mathrm{H}\right\}$ NMR spectrum indicative of an $\left[\mathrm{AlCl}_{4}\right]^{-}$counterion. $\mathrm{BPhCl}$ formazanate 8 was also used to synthesize the four-coordinate (boronium) cation $10^{+}$via treatment with AgOTf (OTf $=$trifluoromethanesulfonate) followed by the addition of one equivalent of 4dimethylaminopyridine (DMAP). The resulting dark-red solid was isolated in $92 \%$ yield and displayed a broad singlet in the ${ }^{11} \mathrm{~B}\left\{{ }^{1} \mathrm{H}\right\}$ NMR centred at $1.9 \mathrm{ppm}$ and a sharp singlet in the ${ }^{19} \mathrm{~F}$ NMR spectrum at $-77.5 \mathrm{ppm}$. Attempts to prepare $10^{+}$by the addition of DMAP to $\mathbf{9}^{+}$resulted in the regeneration of 8 and DMAP.AICl 3 .

$\mathrm{BCl}_{2}$ formazanate $11^{[26 \mathrm{c}]}$ served as a precursor to complexes $12^{+}, 13^{2+}$, and 14 , the last of which has been reported previously. ${ }^{[26 c]}$ Complex 11 was converted to the four-coordinate boronium cation $\mathbf{1 2}^{+}$by treatment with lithium dibenzoylmethanate in $\mathrm{CH}_{2} \mathrm{Cl}_{2}$ and isolated as a red solid in $94 \%$ yield after recrystallization. Treatment of $\mathrm{BCl}_{2}$ formazanate 11 with two equivalents of AgOTf, followed by the addition of bis(diphenylphosphino)methane dioxide (dppmo), afforded a phosphine oxide-stabilized boron dication $13^{2+}$ as an orange powder in $88 \%$ yield. The ${ }^{11} \mathrm{~B}\left\{{ }^{1} \mathrm{H}\right\}$ NMR spectra for $12^{+}$and $13^{2+}$ were centred at 1.9 and $0.0 \mathrm{ppm}$, respectively. The latter also displayed sharp singlets in the ${ }^{19} \mathrm{~F}$ and ${ }^{31} \mathrm{P}\left\{{ }^{1} \mathrm{H}\right\}$ NMR spectra $\left({ }^{19} \mathrm{~F}:-78.2 \mathrm{ppm} ;{ }^{31} \mathrm{P}\left\{{ }^{1} \mathrm{H}\right\}: 54.9 \mathrm{ppm}\right)$.

Single crystals of complexes $8,9^{+}, 12^{+}$, and $13^{2+}$ were analyzed by X-ray diffraction (Figure 1 and Tables S1 and S2). The C-N and N-N bond length in complexes $8,9^{+}, 1^{+}$, and $13^{2+}$ range from $1.334(7)$ to $1.356(7) \AA$ and $1.307(2)$ to $1.325(6) \AA$, respectively. These values fall in between the standard lengths of the respective single and double bonds, suggesting that the $\pi$ electrons of the formazanate backbone are delocalized. ${ }^{[27]}$ Borenium cation $\mathbf{9}^{+}$in particular features a markedly shorter average B-N bond length of 1.451(4) $\AA$ compared to complexes $8,12^{+}$, and $13^{2+}[1.545(5) \AA]$. This length reduction suggests a bond order greater than 1 and can be linked to the fact that $\mathbf{9}^{+}$ possesses an $s p^{2}$-hybrized boron atom capable of participating

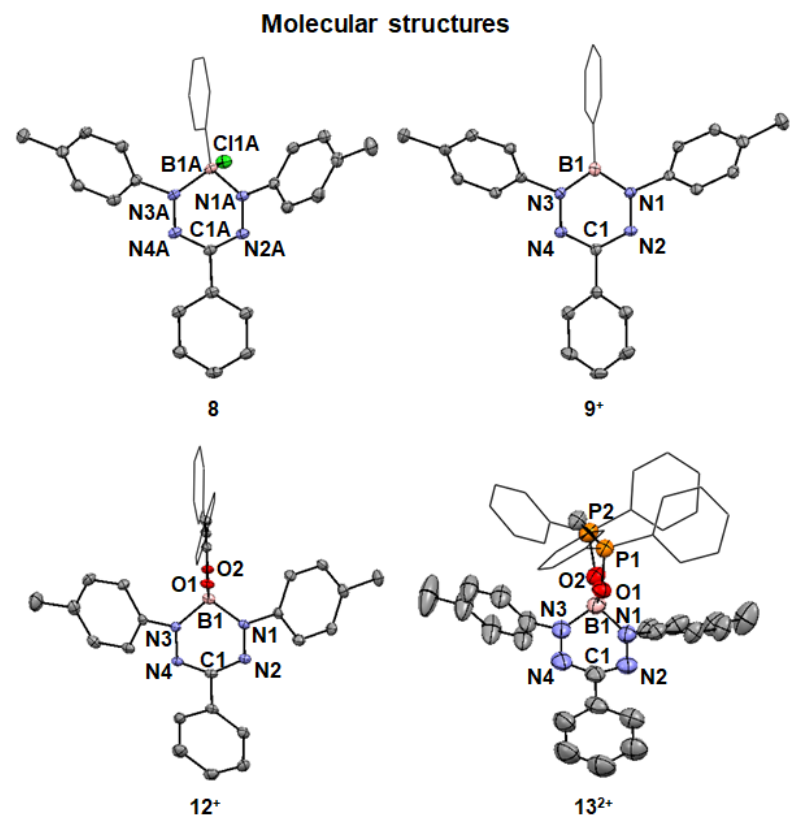

Side views of the $\mathrm{CN}_{4} \mathrm{~B}$ ring
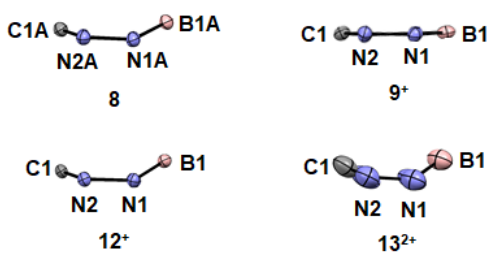

Figure 1. Experimental solid-state structures of four crystallized boron formazanate complexes. For clarity, hydrogen atoms are omitted and phenyl groups are shown as wireframes. 
in $\pi$-electron delocalization via resonance. Further analysis revealed that the $s p^{3}$-hybridized boron atoms in complexes $\mathbf{8}$, $12^{+}$, and $13^{2+}$ are displaced from the plane defined by the four nitrogen atoms of the formazanate backbones (N1, N2, N3, N4) by a minimum of $0.380(3) \AA$, whereas the boron atom in complex $9^{+}$lies within 0.041(4) $\AA$ of that plane. The planes defined by the $N$-aryl substituents and the four nitrogen atoms of the formazanate ligand are offset by at least $48.59(7)^{\circ}$ in $\mathbf{8}, \mathbf{9}^{+}$, $12^{+}$, and $13^{2+}$. Thus, the boron formazanate $\left(\mathrm{CN}_{4} \mathrm{~B}\right)$ ring is almost planar in $\mathbf{9}^{+}$and has a boat-like conformation in the other three complexes (Figure 1).

UV-vis absorption spectroscopy data for $\mathbf{8}-\mathbf{1 0}^{+}$(in toluene) and $12^{+}-14$ (in $\mathrm{CH}_{2} \mathrm{Cl}_{2}$ ) are presented in Figure 2a and Table 1. The choice of solvent was determined by the stability and solubility of each compound. Complexes $8,9^{+}$, and $10^{+}$exhibit broad absorption bands with molar extinction coefficients $(\varepsilon)$ ranging from 6300 to $12100 \mathrm{M}^{-1} \mathrm{~cm}^{-1}$. Complex 8, which features a four-coordinate neutral boron atom, has a maximum absorption wavelength $\left(\lambda_{\max }\right)$ of $521 \mathrm{~nm}\left(\varepsilon=12100 \mathrm{M}^{-1} \mathrm{~cm}^{-1}\right)$, consistent with other neutral four-coordinate boron adducts of formazanates. ${ }^{[23 a, 23 b]}$ The low-energy absorption band of $10^{+}$, a molecule with a four-coordinate cationic boron atom, is moderately blue-shifted and has a lower intensity relative to the neutral BPhCl adduct $8\left(\lambda_{\max }=510 \mathrm{~nm}, \varepsilon=8300 \mathrm{M}^{-1} \mathrm{~cm}^{-1}\right)$. By contrast, the low-energy absorption band of three-coordinate boron cation $\mathbf{9}^{+}$is strongly red-shifted $\left(\lambda_{\max }\right.$ of $597 \mathrm{~nm}, \varepsilon=6300$ $\mathrm{M}^{-1} \mathrm{~cm}^{-1}$ ) relative to complexes 8 and $10^{+}$. The magnitudes of these shifts indicate that the coordination number of the cationic boron centres can exert a strong influence on the position of the lowest-energy absorption maximum. Complexes $14,1^{+}$, and $13^{2+}$ feature $\lambda_{\max }$ values of $549 \mathrm{~nm}\left(\varepsilon=18000 \mathrm{M}^{-1} \mathrm{~cm}^{-1}\right), 540 \mathrm{~nm}$ $\left(\varepsilon=5900 \mathrm{M}^{-1} \mathrm{~cm}^{-1}\right)$, and $505 \mathrm{~nm}\left(\varepsilon=9400 \mathrm{M}^{-1} \mathrm{~cm}^{-1}\right)$, respectively. This suggests that the lowest excitation energies of boron formazanate complexes with a fixed coordination number increase with increasing positive charge at boron.

To gain a better understanding of these observations, we investigated complexes $8-10^{+}$and $12^{+}-14$ using approximate density-functional theory (DFT). The computational methodology is documented in the Supporting Information; the results are summarized in Table 1 and Figures $2 \mathrm{~b}$ and S25. The calculations show that, in all cases, the dominant orbital pair associated with the lowest-energy electronic absorption band involves the highest occupied molecular orbital (HOMO) and the lowest unoccupied molecular orbital (LUMO). All of the lowestenergy excitations in $8-10^{+}$and $12^{+}-14$ are of $\Pi \rightarrow \pi^{*}$ type (Figure $2 \mathrm{~b}$ ). Among the six complexes $8-10^{+}$and $12^{+}-14$, only one $\left(9^{+}\right)$has a flat six-membered $\mathrm{CN}_{4} \mathrm{~B}$ ring, while in the other five the same ring is in a boat-like conformation. The difference is clearly seen both in the experimental (Figure 1) and calculated geometries of these complexes.
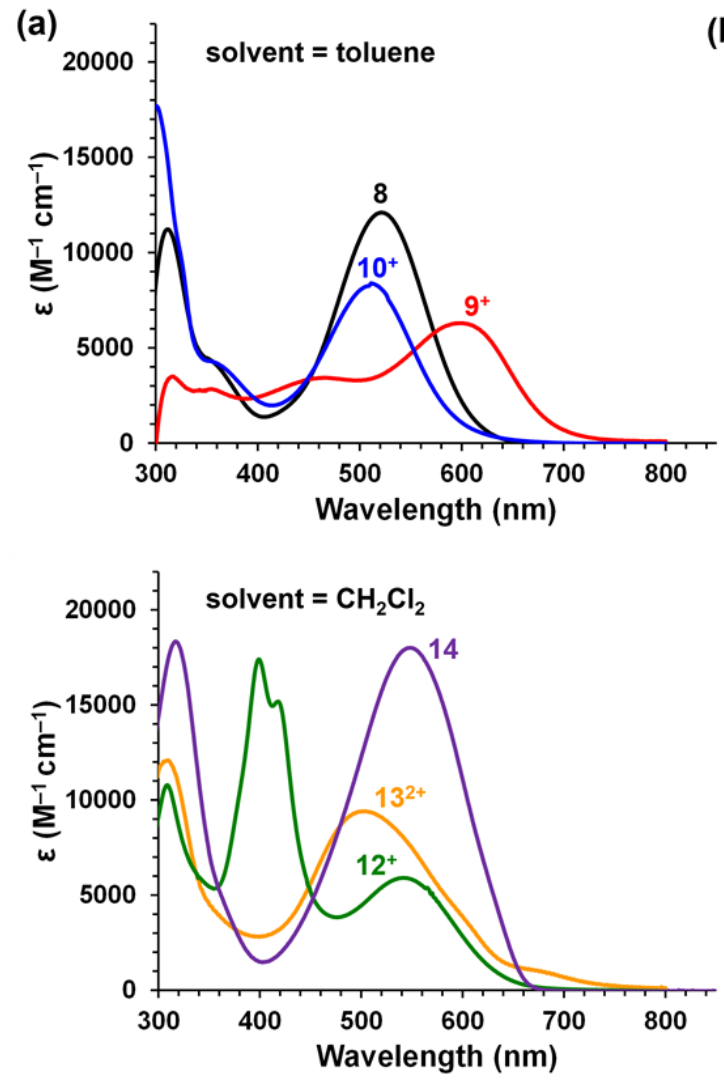

(b) LUMO

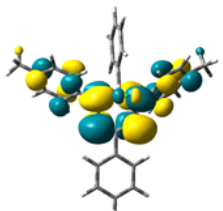

HOMO

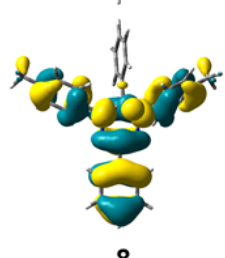

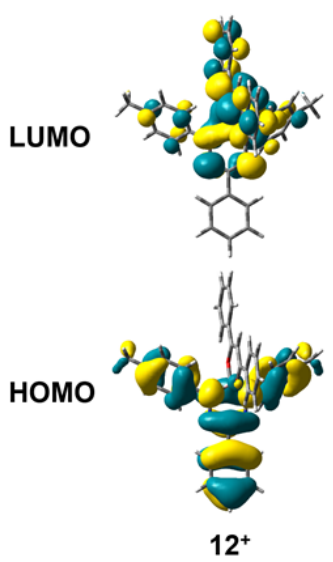

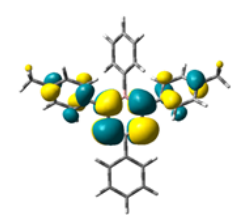

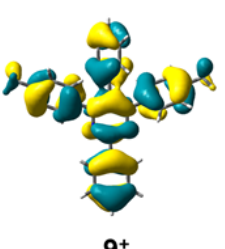

$9^{+}$
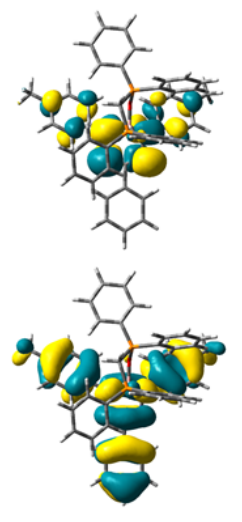

$13^{2+}$
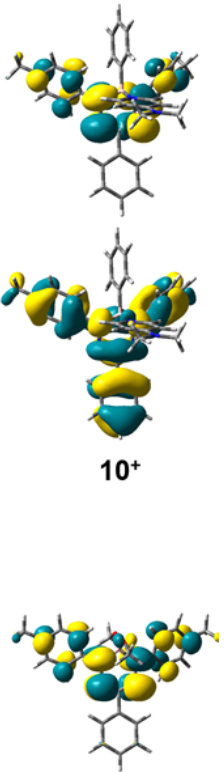

$10^{+}$

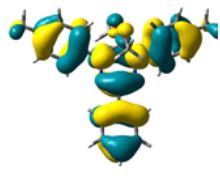

14

Figure 2. (a) UV-vis absorption spectra of $10^{-6} \mathrm{M}$ dry degassed solutions of complexes $8-10^{+}$and $12^{+}-14$. (b) Frontier molecular orbitals of complexes $8-10^{+}$ and $12^{+}-14$. 
Table 1. Experimental and simulated spectroscopic properties of complexes $8-10^{+}$and $12^{+}-14$ in solution. The theoretical values were calculated by timedependent DFT using the PBE1PBE/DGDZVP2 SCRF=CPCM method.

\begin{tabular}{|c|c|c|c|c|c|c|c|}
\hline \multirow{2}{*}{ Complex } & \multirow{2}{*}{ Supporting ligands at boron } & \multirow{2}{*}{ Solvent } & \multicolumn{2}{|c|}{ Experiment } & \multicolumn{3}{|c|}{ Theory } \\
\hline & & & $\lambda_{\max }(\mathrm{nm})$ & $\varepsilon\left(\mathrm{M}^{-1} \mathrm{~cm}^{-1}\right)$ & $\lambda_{\max }(\mathrm{nm})$ & Intensity & Transition \\
\hline 8 & $\mathrm{Ph}, \mathrm{Cl}$ & toluene & 521 & 12100 & 507 & 0.417 & $\mathrm{HOMO} \rightarrow \mathrm{LUMO}$ \\
\hline $9^{+}$ & $\mathrm{Ph}$ & toluene & 597 & 6300 & 637 & 0.259 & $\mathrm{HOMO} \rightarrow \mathrm{LUMO}$ \\
\hline $10^{+}$ & $\mathrm{Ph}, \mathrm{DMAP}$ & toluene & 510 & 8300 & 502 & 0.401 & $\mathrm{HOMO} \rightarrow \mathrm{LUMO}$ \\
\hline $12^{+}$ & dibenzoylmethanate & $\mathrm{CH}_{2} \mathrm{Cl}_{2}$ & 540 & 5900 & 569 & 0.134 & $\mathrm{HOMO} \rightarrow \mathrm{LUMO}$ \\
\hline $13^{2+}$ & dppmo & $\mathrm{CH}_{2} \mathrm{Cl}_{2}$ & 505 & 9400 & 514 & 0.308 & $\mathrm{HOMO} \rightarrow \mathrm{LUMO}$ \\
\hline 14 & $(\mathrm{OMe})_{2}$ & $\mathrm{CH}_{2} \mathrm{Cl}_{2}$ & 549 & 18000 & 546 & 0.500 & $\mathrm{HOMO} \rightarrow \mathrm{LUMO}$ \\
\hline
\end{tabular}

The four-coordinate complexes 8 and $10^{+}$have nearly identical geometries of the $\mathrm{CN}_{4} \mathrm{~B}$ ring, almost superimposable HOMOs and LUMOs (Figure $2 b$ ), and approximately equal $\lambda_{\max }$ values. The modest $11 \mathrm{~nm}$ blue shift exhibited by $10^{+}$relative to 8 (in toluene) may be attributed to the positive charge of the boron atom. The three-coordinate complex $9^{+}$has the same +1 charge at boron as $10^{+}$but a much greater $\lambda_{\max }$ value (a red shift by $76 \mathrm{~nm}$ ) and a lower intensity of the first transition. The most plausible reason for this dramatic red shift is the flat geometry of the $\mathrm{CN}_{4} \mathrm{~B}$ ring in $\mathbf{9}^{+}$, which enables the $\mathrm{HOMO}$ to extend into the phenyl substituent at boron and reduces the HOMO-LUMO gap. The three four-coordinate complexes $12^{+}-14$ have similar nonplanar $\mathrm{CN}_{4} \mathrm{~B}$ rings and look-alike HOMOs. As a result, the maximum absorption wavelengths in this set vary over a narrower range (44 $\mathrm{nm}$ in $\mathrm{CH}_{2} \mathrm{Cl}_{2}$ ) and are strictly correlated with the charges at boron: $\lambda_{\max }(14)>\lambda_{\max }\left(12^{+}\right)>\lambda_{\max }\left(13^{2+}\right)$.

Closer examination of the HOMO-LUMO pairs for complexes $8-10^{+}$and $12^{+}-14$ suggests that the lowest-energy transitions in two of them, $\mathbf{9}^{+}$and $12^{+}$, must be accompanied by partial charge transfer between the boron formazanate rings and supporting ligands at boron. This conclusion is supported by the substantial overestimation of the calculated $\lambda_{\max }$ values for $\mathbf{9}^{+}$and $\mathbf{1 2}^{+}$ relative to experiment (Table 1 ) because standard density functional such as PBE1PBE are known to underestimate the energies of charge-transfer excitations. ${ }^{[28]}$ These results show that supporting ligands at boron can alter not only the wavelength but also the type of low-energy electronic transitions.

In summary, we have synthesized a series of boron-based cations supported by formazanate ligands with the aim to investigate the influence of charge and coordination number at boron on the electronic properties of BN heterocycles. Our conclusions are as follows: i) an increase in the cationic charge on boron in four-coordinate compounds (e.g., $10^{+}$and $13^{2+}$ ) blue-shifts $\lambda_{\max }$ and decreases the intensities of the lowestenergy absorption bands; ii) introduction of a planar, 3coordinate cationic boron atom (as in $\mathbf{9}^{+}$) extends $\pi$-conjugation in the HOMO and dramatically red-shifts $\lambda_{\max }$; iii) chelating $\pi$ conjugated supporting ligands (as in $1^{+}$) reorganize the electronic structure and red-shift $\lambda_{\max }$ by inducing charge transfer. Collectively, this work establishes guiding principles for the design of optoelectronic molecular materials featuring cationic boron fragments that can be applied to $\pi$-conjugated heterocycles containing other main-group elements.

\section{Acknowledgements}

This work was supported by the Natural Sciences and Engineering Research Council (NSERC) of Canada (V.N.S.: DG, RGPIN-2020-06420; J.B.G.: DG, RGPIN-2018-04240, R.R.M.: CGS-D Scholarship), the Ontario Ministry of Research and Innovation (J.B.G.: ERA, ER-14-10-147), and the Canadian Foundation for Innovation (J.B.G.: JELF, 33977).

Keywords: Borenium, boronium, formazanate ligands, BN heterocycles, optoelectronic materials.

[1] R. L. Melen, Science 2019, 363, 479-484

[2] J. Lam, K. M. Szkop, E. Mosaferi, D. W. Stephan, Chem. Soc. Rev. 2019, 48, 3592-3612.

[3] T. Chu, G. I. Nikonov, Chem. Rev. 2018, 118, 3608-3680.

[4] G. C. Welch, R. R. S. Juan, J. D. Masuda, D. W. Stephan, Science 2006, 314, 1124-1126.

[5] T. Baumgartner, F. Jäkle, Main Group Strategies towards Functional Hybrid Materials, Wiley, Chichester, 2018.

[6] M. Hirai, N. Tanaka, M. Sakai, S. Yamaguchi, Chem. Rev. 2019, 119, 8291-8331.

[7] a) F. Jäkle, Chem. Rev. 2010, 110, 3985-4022; b) L. Ji, S. Griesbeck, T. B. Marder, Chem. Sci. 2017, 8, 846-863; c) S. K. Mellerup, S. Wang, Trends in Chemistry 2019, 1, 77-89.

[8] H. Braunschweig, T. Kupfer, Chem. Commun. 2011, 47, 10903-10914.

[9] a) A. Y. Houghton, J. Hurmalainen, A. Mansikkamäki, W. E. Piers, H. M. Tuononen, Nat. Chem. 2014, 6, 983-988; b) Z. Zhang, R. M. Edkins, M. Haehnel, M. Wehner, A. Eichhorn, L. Mailänder, M. Meier, J. Brand, F. Brede, K. Müller-Buschbaum, H. Braunschweig, T. B. Marder, Chem. Sci. 2015, 6, 5922-5927; c) J. H. Barnard, S. Yruegas, K. Huang, C. D. Martin, Chem. Commun. 2016, 52, 9985-9991.

[10] I. B. Sivaev, V. I. Bregadze, Coord. Chem. Rev. 2014, 270-271, 75-88.

[11] a) W. Yang, K. E. Krantz, L. A. Freeman, D. A. Dickie, A. Molino, A Kaur, D. J. D. Wilson, R. J. Gilliard Jr., Chem. Eur. J. 2019, 25, 12512 12516; b) Y. Adachi, F. Arai, F. Jäkle, Chem. Commun. 2020, 56, 5119-5122.

[12] a) T. Scherpf, K.-S. Feichtner, V. H. Gessner, Angew. Chem. Int. Ed. 2017, 56, 3275-3279; b) N. Tanaka, Y. Shoji, D. Hashizume, M. Sugimoto, T. Fukushima, Angew. Chem. Int. Ed. 2017, 56, 5312-5316; c) H.-C. Tseng, C.-T. Shen, K. Matsumoto, D.-N. Shih, Y.-H. Liu, S.-M. Peng, S. Yamaguchi, Y.-F. Lin, C.-W. Chiu, Organometallics 2019, 38, 4516-4521.

[13] W.-H. Lee, Y.-F. Lin, G.-H. Lee, S.-M. Peng, C.-W. Chiu, Dalton Trans. 2016, 45, 5937-5940

[14] a) C. Bonnier, W. E. Piers, M. Parvez, T. S. Sorensen, Chem. Commun. 2008, 4593-4595; b) E. Tsurumaki, S.-y. Hayashi, F. S. Tham, C. A. Reed, A. Osuka, J. Am. Chem. Soc. 2011, 133, 11956-11959; c) D. Franz, E. Irran, S. Inoue, Angew. Chem. Int. Ed. 2014, 53, 14264- 
14268; d) M. Devillard, R. Brousses, K. Miqueu, G. Bouhadir, D. Bourissou, Angew. Chem. Int. Ed. 2015, 54, 5722-5726; e) J. M. Farrell D. W. Stephan, Angew. Chem. Int. Ed. 2015, 54, 5214-5217; f) J. A. B. Abdalla, R. C. Tirfoin, H. Niu, S. Aldridge, Chem. Commun. 2017, 53, 5981-5984; g) Y. K. Loh, K. Porteous, M. Á. Fuentes, D. C. H. Do, J. Hicks, S. Aldridge, J. Am. Chem. Soc. 2019, 141, 8073-8077; h) T. Janes, Y. Diskin-Posner, D. Milstein, Angew. Chem. Int. Ed. 2020, 59, 4932-4936; i) T. Heitkemper, C. Sindlinger, Chem. Eur. J. 2020, 26, 11684-11689.

[15] W.-C. Chen, C.-Y. Lee, B.-C. Lin, Y.-C. Hsu, J.-S. Shen, C.-P. Hsu, G. P. A. Yap, T.-G. Ong, J. Am. Chem. Soc. 2014, 136, 914-917.

[16] a) T. W. Hudnall, F. P. Gabbaï, Chem. Commun. 2008, 4596-4597; b) A. Prokofjevs, J. W. Kampf, A. Solovyev, D. P. Curran, E. Vedejs, J. Am. Chem. Soc. 2013, 135, 15686-15689; c) L. Kong, W. Lu, Y. Li, R. Ganguly, R. Kinjo, J. Am. Chem. Soc. 2016, 138, 8623-8629; d) W. Lu, Y. Li, R. Ganguly, R. Kinjo, Angew. Chem. Int. Ed. 2017, 56, 98299832; e) S. Rixin Wang, M. Arrowsmith, H. Braunschweig, R. D. Dewhurst, V. Paprocki, L. Winner, Chem. Commun. 2017, 53, 1194511947 ; f) S. J. Geier, C. M. Vogels, N. R. Mellonie, E. N. Daley, A. Decken, S. Doherty, S. A. Westcott, Chem. Eur. J. 2017, 23, 1448514499; g) S. Hagspiel, M. Arrowsmith, F. Fantuzzi, A. Hermann, V. Paprocki, R. Drescher, I. Krummenacher, H. Braunschweig, Chem. Sci. 2020, 11, 551-555.

[17] a) H. Schmidbaur, T. Wimmer, G. Reber, G. Müller, Angew. Chem. Int. Ed. Engl. 1988, 27, 1071-1074; b) D. Vidovic, M. Findlater, A. H. Cowley, J. Am. Chem. Soc. 2007, 129, 8436-8437; c) H. Braunschweig, M. Kaupp, C. Lambert, D. Nowak, K. Radacki, S. Schinzel, K. Uttinger, Inorg. Chem. 2008, 47, 7456-7458; d) G. P. McGovern, D. Zhu, A. J. A. Aquino, D. Vidović, M. Findlater, Inorg. Chem. 2013, 52, 13865-13868.

[18] a) R. Kinjo, B. Donnadieu, M. A. Celik, G. Frenking, G. Bertrand, Science 2011, 333, 610-613; b) C.-T. Shen, Y.-H. Liu, S.-M. Peng, C.W. Chiu, Angew. Chem. Int. Ed. 2013, 52, 13293-13297; c) Y. Shoji, N. Tanaka, K. Mikami, M. Uchiyama, T. Fukushima, Nat. Chem. 2014, 6, 498-503; d) M. Devillard, S. Mallet-Ladeira, G. Bouhadir, D. Bourissou, Chem. Commun. 2016, 52, 8877-8880; e) D. Franz, T. Szilvási, A. Pöthig, F. Deiser, S. Inoue, Chem. Eur. J. 2018, 24, 4283-4288.

[19] P. Eisenberger, C. M. Crudden, Dalton Trans. 2017, 46, 4874-4887.

[20] a) W. E. Piers, S. C. Bourke, K. D. Conroy, Angew. Chem. Int. Ed. 2005, 44, 5016-5036; b) D. Franz, S. Inoue, Chem. Eur. J. 2019, 25, 2898 2926.
[21] J. B. Gilroy, E. Otten, Chem. Soc. Rev. 2020, 49, 85-113.

[22] a) M.-C. Chang, T. Dann, D. P. Day, M. Lutz, G. G. Wildgoose, E. Otten, Angew. Chem. Int. Ed. 2014, 53, 4118-4122; b) M.-C. Chang, E. Otten Chem. Commun. 2014, 50, 7431-7433; c) R. Travieso-Puente, M.-C. Chang, E. Otten, Dalton Trans. 2014, 43, 18035-18041; d) R. TraviesoPuente, J. O. P. Broekman, M.-C. Chang, S. Demeshko, F. Meyer, E. Otten, J. Am. Chem. Soc. 2016, 138, 5503-5506; e) R. Mondol, D. A Snoeken, M.-C. Chang, E. Otten, Chem. Commun. 2017, 53, 513-516; f) E. Kabir, C.-H. Wu, J. I.-C. Wu, T. S. Teets, Inorg. Chem. 2016, 55, 956-963; g) E. Kabir, G. Mu, D. A. Momtaz, N. A. Bryce, T. S. Teets, Inorg. Chem. 2019, 58, 11672-11683; h) D. L. J. Broere, B. Q. Mercado, P. L. Holland, Angew. Chem. Int. Ed. 2018, 57, 6507-6511; i) R. R. Maar, A. Rabiee Kenaree, R. Zhang, Y. Tao, B. D. Katzman, V. N. Staroverov, Z. Ding, J. B. Gilroy, Inorg. Chem. 2017, 56, 12436-12447; j) R. R. Maar, S. D. Catingan, V. N. Staroverov, J. B. Gilroy, Angew. Chem. Int. Ed. 2018, 57, 9870-9874.

[23] a) S. M. Barbon, J. T. Price, P. A. Reinkeluers, J. B. Gilroy, Inorg. Chem. 2014, 53, 10585-10593; b) S. M. Barbon, V. N. Staroverov, J. B. Gilroy, J. Org. Chem. 2015, 80, 5226-5235; c) M.-C. Chang, A. Chantzis, D. Jacquemin, E. Otten, Dalton Trans. 2016, 45, 9477-9484; d) A. Melenbacher, J. S. Dhindsa, J. B. Gilroy, M. J. Stillman, Angew. Chem. Int. Ed. 2019, 58, 15339-15343; e) R. R. Maar, R. Zhang, D. G. Stephens, Z. Ding, J. B. Gilroy, Angew. Chem. Int. Ed. 2019, 58, 10521056.

[24] R. R. Maar, S. M. Barbon, N. Sharma, H. Groom, L. G. Luyt, J. B. Gilroy, Chem. Eur. J. 2015, 21, 15589-15599.

[25] a) M. Hesari, S. M. Barbon, V. N. Staroverov, Z. Ding, J. B. Gilroy, Chem. Commun. 2015, 51, 3766-3769; b) M. Hesari, S. M. Barbon, R. B. Mendes, V. N. Staroverov, Z. Ding, J. B. Gilroy, J. Phys. Chem. C 2018, 122, 1258-1266.

[26] a) M.-C. Chang, E. Otten, Inorg. Chem. 2015, 54, 8656-8664; b) S. M. Barbon, V. N. Staroverov, J. B. Gilroy, Angew. Chem. Int. Ed. 2017, 56, 8173-8177; c) R. R. Maar, N. A. Hoffman, V. N. Staroverov, J. B. Gilroy, Chem. Eur. J. 2019, 25, 11015-11019.

[27] J. R. Rumble, CRC Handbook of Chemistry and Physics, 98th ed., CRC Press/Taylor and Francis, Boca Raton, FL.

[28] a) Y. Tawada, T. Tsuneda, S. Yanagisawa, T. Yanai, K. Hirao, J. Chem. Phys. 2004, 120, 8425-8433; b) T. Yanai, D. P. Tew, N. C. Handy, Chem. Phys. Lett. 2004, 393, 51-57; c) S. Kümmel, Adv. Energy Mater. 2017, 7, 1700440 . 